Review

\title{
Mesenchymal Stem Cell-Dependent Modulation of Liver Diseases
}

\author{
Marina Gazdic ${ }^{1}$, Aleksandar Arsenijevic ${ }^{2}$, Bojana Simovic Markovic², Ana Volarevic ${ }^{2}$, Ivanka Dimova ${ }^{3}$, \\ Valentin Djonov ${ }^{4}$, Nebojsa Arsenijevic ${ }^{2}$, Miodrag Stojkovic ${ }^{1,5}$ and Vladislav Volarevic ${ }^{2}$ \\ 1. University of Kragujevac, Serbia, Faculty of Medical Sciences, Department of Genetics; \\ 2. University of Kragujevac, Serbia, Faculty of Medical Sciences, Department of Microbiology and immunology, Center for Molecular Medicine and Stem Cell \\ Research; \\ 3. Department of medical genetics, Medical University Sofia, Sofia, Bulgaria; \\ 4. Institute of Anatomy, University of Bern, Bern, Switzerland; \\ 5. Spebo Medical, Leskovac, Serbia.
}

$\square$ Corresponding author: Prof. dr Vladislav Volarevic, Center for Molecular Medicine and Stem Cell Research, Faculty of Medical Sciences University of Kragujevac, Kragujevac, Serbia; 69 Svetozara Markovica Street, 34000 Kragujevac, Serbia e mail: drvolarevic@yahoo.com, Phone: +38134306800, fax: +3813430600 ext.112

(c) Ivyspring International Publisher. This is an open access article distributed under the terms of the Creative Commons Attribution (CC BY-NC) license (https://creativecommons.org/licenses/by-nc/4.0/). See http://ivyspring.com/terms for full terms and conditions.

Received: 2017.03.24; Accepted: 2017.05.27; Published: 2017.09.05

\begin{abstract}
Acute liver failure and cirrhosis display sequential and overlapping severe pathogenic processes that include inflammation, hepatocyte necrosis, and fibrosis, carrying a high mortality rate. Mesenchymal stem cells (MSCs) are a heterogeneous subset of stromal stem cells with immunonodulatory characteristics. MSCs are considered to act through multiple mechanisms to coordinate a dynamic, integrated response to liver inflammation and fibrosis, which prevents the progressive distortion of hepatic architecture. Accordingly, MSCs as well as their products have been investigated as a novel therapeutic approach for the treatment of inflammatory and fibrotic liver diseases.

In this review, we highlight the current findings on the MSC-based modulation of liver inflammation and fibrosis, and the possible use of MSCs in the therapy of immune-mediated liver pathology. We briefly describe the cellular and molecular mechanisms involved in MSC-dependent modulation of cytokine production, phenotype and function of liver infiltrated inflammatory cells and compare effects of engrafted MSCs versus MSC-generated conditioned medium (MSC-CM) in the therapy of acute liver injury. In order to elucidate therapeutic potential of MSCs and their products in modulation of chronic liver inflammation and fibrosis, we present the current findings regarding pathogenic role of immune cells in liver fibrosis and describe mechanisms involved in MSC-dependent modulation of chronic liver inflammation with the brief overview of on-going and already published clinical trials that used MSCs for the treatment of immune mediated chronic liver diseases. The accumulating evidence shows that MSCs had a significant beneficial effect in the treatment of immune-mediated liver diseases.
\end{abstract}

Key words: mesenchymal stem cells, immune response, acute liver failure, cirrhosis, therapy.

\section{Introduction}

Abnormal innate and adaptive immune responses and unbalanced immune cell infiltration can disrupt the immune-privileged state of the liver, resulting in inflammation-associated damage of hepatocytes. Acute liver failure and cirrhosis display sequential and overlapping severe pathogenic processes that include inflammation, hepatocyte necrosis, fibrosis, and carry a high mortality rate (1).

Last decades' preclinical and clinical trials have led to application of stem cells as a novel therapeutic agent for the treatment of degenerative and immune-mediated diseases. Mesenchymal stem cells (MSCs) are a heterogeneous subset of stromal stem cells with immunonodulatory characteristics. Recent studies have shown that MSCs-based therapies may reduce liver inflammation, and subsequently improve regeneration of hepatocytes, which could be a promising strategy for patients with immune- 
mediated liver injuries.

Although MSCs transdifferentiation into hepatocytes has been demonstrated in vitro, the vast majority of recently published studies indicated that therapeutic effects and use of MSCs in acute and chronic liver failure would be primarily based on their immunomodulatory properties (2). As a result of preclinical studies, MSCs are now considered to intuitively respond to the inflammatory environment and to modulate function of immune cells through the release of soluble factors and/or through cell contact signaling (3).

MSCs alter the secretion profile of dendritic cells (DCs) resulting in increased production of anti-inflammatory cytokine interleukin (IL)-10 and decreased production of tumor necrosis factor alpha (TNF- $\alpha)$, interferon-gamma (IFN- $\gamma$ ), and IL-12 (4). Immature DCs generated in the presence of MSCs do not express major histocompatibility complex class II (MHCII) molecule and costimulatory molecules cluster of differentiation (CD) 40, CD80 and CD86, and are able to render $\mathrm{T}$ helper type 1(Th1) cell anergic (5).

Several research groups emphasized an important role of transforming growth factor (TGF- $\beta$ ), hepatocyte growth factor (HGF), prostaglandin E2 $\left(\mathrm{PGE}_{2}\right)$ and heme-oxygenase-1 (HO-1), as well as the engagement of the inhibitory molecule programmed death 1 (PD-1) with its ligands PD-L1 and PD-L2 for MSC-dependent suppression of $\mathrm{CD}^{+}$and $\mathrm{CD} 8^{+} \mathrm{T}$-cell proliferation $(4,5)$. Additionally, through secretion of $\mathrm{PGE}_{2}$, MSCs reduce production of IFN- $\gamma$ and IL-4 in Th1 and T helper type 2 (Th2) cells and stimulate generation and proliferation of immunosuppressive $\mathrm{CD}^{+}{ }^{+} \mathrm{CD} 25^{+}$forhead box P3 (FoxP3)+ (Tregs) $(2,5)$. Through cell to cell contact and through paracrine mechanisms mediated by indoleamine 2,3-dioxygenase (IDO), PGE2 and TGF- $\beta$, MSCs are able to inhibit cytotoxic CD8+ T lymphocytes (CTLs) and natural killer (NK) cells (2).

Classically activated (M1) macrophages (stimulated by Toll-like receptor (TLR) ligands and IFN- $\gamma$ ) produce high levels of proinflammatory cytokines, reactive nitrogen and oxygen species, and are implicated in initiating and sustaining inflammation (6). In contrast, alternatively activated (M2) macrophages (stimulated by IL-4/IL-13) are less toxic to microbes and have anti-inflammatory and reparative functions (6). As a result, a switch from M1 to M2 phenotype is crucial for resolution of inflammation and tissue remodeling. MSC-mediated polarization of resident macrophages from classic M1 pro-inflammatory phenotype, toward anti-inflammatory M2 phenotype is dependent on both cellular contact and secretion of soluble factors, including $\mathrm{PGE}_{2}, \mathrm{TNFa}$ stimulated gene/protein 6 (TSG-6), IL-6, and IDO (3). Also, MSCs exert their suppressive effect on antibody production as well as proliferation of activated $\mathrm{B}$ lymphocytes in an IDO-dependent manner (5).

Due to their immunomodulatory characteristics MSCs have been extensively investigated as a novel therapeutic approach for the treatment of inflammatory and fibrotic liver diseases. Huge number of animal models of acute and chronic liver failure, that resemble the pathology of immune-mediated liver damage in humans, have demonstrated not only therapeutic efficacy of culture-expanded MSCs, but also the mechanism of interactions between MSCs and immune cells that may be of relevance to future widespread clinical use of MSCs in therapy of liver diseases.

In this review, we highlight the current findings on the MSC-based modulation of acute liver injury and fibrosis, and the possible use of MSCs in the therapy of liver pathology.

\section{MSC-mediated attenuation of acute liver failure}

In order to emphasize cellular and molecular mechanisms involved in MSC-mediated attenuation of acute liver failure, we briefly described the current findings regarding pathogenic role of immune cells in this process, present information related to MSC-dependent modulation of cytokine production, phenotype and function of liver infiltrated inflammatory cells and compare effects of engrafted MSCs versus MSC-generated conditioned medium (MSC-CM).

\section{Cellular and molecular mechanisms involved in acute liver failure}

The mechanisms that cause acute liver failure are divided into two phases. Firstly, pathogen and toxin disturb intracellular homeostasis and directly damage liver cells (7). Secondly, to control liver injury progression, the immune system must distinguish between evasion and tissue damage, both of which elicit similar inflammatory immune responses (7). All of these mechanisms, contribute to hepatocyte apoptosis, autophagy, necrosis and necroptosis, and lead to immune-mediated liver injury (7).

A variety of animal models have been used to study the mechanisms of acute liver injury, such as those induced by chemical substances, metabolic substances, infectious pathogens and surgery models. Concanavalin A (Con A)-induced liver injury is a well-established murine model of immune- mediated hepatitis $(8,9)$. Our previous studies showed that Con A-induced hepatitis is an ideal model for the 
analysis of initial and fundamental events in the development of T-cell dependent liver disorders $(8,9$, $10,11)$. $\mathrm{CD}^{+} \mathrm{T}$ lymphocytes infiltrate the liver tissue and secrete large amounts of cytokines, such as TNF-a, IFN- $\gamma$, IL-2, and granulocyte macrophage colony stimulating factor (GM-CSF) (9). Apart from $\mathrm{CD}^{+} \mathrm{T}$ cells, $\mathrm{CD} 8{ }^{+} \mathrm{T}$ cells, $\mathrm{NK}$, natural killer $\mathrm{T}$ (NKT) cells and macrophages could induce hepatocyte cell death by either cell-to-cell contact, through the secretion of pro-inflammatory cytokines, or reactive oxygen species $(8,9,11)$.

\section{MSC-mediated modulation of cytokine network in acute liver failure}

MSCs may attenuate acute liver inflammation and consequent hepatocyte damage by modulating production of inflammatory cytokines and other inflammation-related molecules in liver-infiltrating immune cells creating hepato-protective environment in the liver (Figure 1).

In Con A-induced liver injury, mice were successfully treated with MSC infusion which resulted with attenuated liver injury as determined by decreased levels of transaminases in serum, reduced necrosis of hepatocytes as well as attenuated production of pro-inflammatory and pro-apoptotic cytokines (TNF- $\alpha$ and IFN- $\gamma$ ) in liver infiltrated immune cells $(12,13)$. TNF- $\alpha$ is directly capable of inducing hepatocyte apoptosis via TNF-receptor signaling induced activation of caspase- 8 , leading to mitochondrial cytochrome $c$ release and caspase-3 activation (14). On the other hand, IFN- $\gamma$ plays a central role in Con A-hepatitis by activating apoptosis stimulating fragment (Fas)-induced apoptosis of liver cells (15).

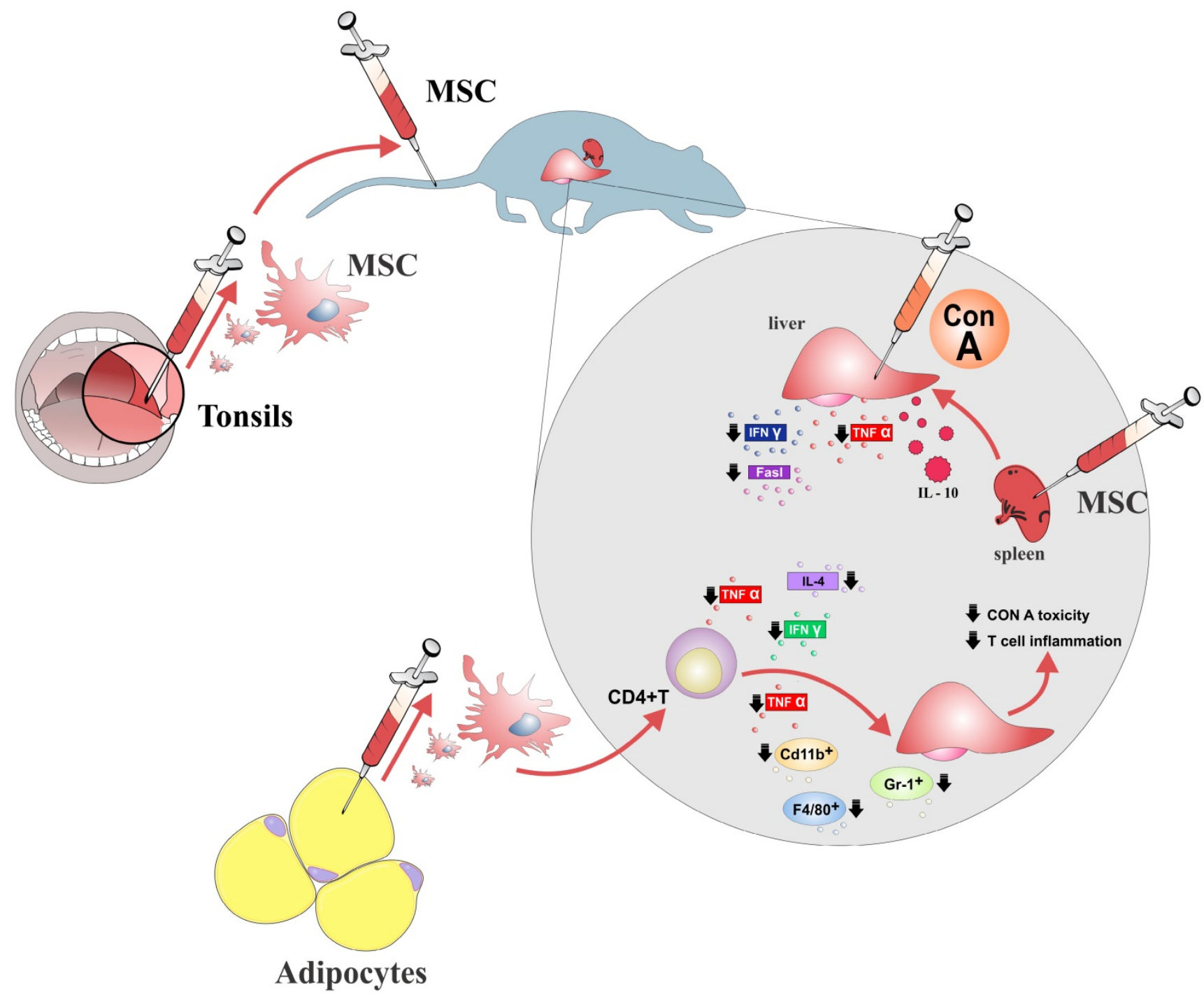

Figure 1. Therapeutic effects of MSCs in acute liver failure. MSCs isolated from different sources ameliorate acute liver injury by reducing the number of major effector cells in hepatic inflammation (CD4+ T lymphocytes, Gr-1+ neutrophils and CDI l b+ F4/80+ macrophages). MSCs restrained acute liver injury through increasing production of protective IL-10 and by decreasing expression of TNF-a, IFN-y, IL-4 and FasL in the CD4+lymphocytes and kupffer cells. 
Since apoptosis is responsible for Con A-induced liver injury (11), the suppressive effects of MSCs on production of TNF- $\alpha$ and IFN- $\gamma$, might explain the reduced apoptotic cell death in liver sinusoidal endothelial cells and hepatocytes, resulting in the amelioration of acute hepatitis. Moreover, it seems that MSC-mediated suppression of inflammatory cytokine production in immune cells is systemic and not limited to the liver area (13). MSCs significantly reduced number of activated lymphocytes throughout the body, attenuated the production of inflammatory cytokines (TNF- $\alpha$, IFN- $\gamma$, IL-4) and increased secretion of immunosuppressive and hepatoprotective IL-10 in the liver and spleen infiltrating lymphocytes, DCs and resident liver macrophages (Kupffer cells) as well as in the serum of MSC-treated mice with acute liver injury $(13,16)$ (Figure 1).

MSCs produce galectin- 1 and galectin-3 which are known as an important immunomodulatory molecules (3). Tonsil-derived mesenchymal stem cells (T-MSCs) through the production of galectin-1, significantly attenuated Con A-induced hepatic toxicity and suppressed inflammatory cytokine secretion in T cells (17) (Figure 1). In line with these findings, we recently demonstrated the importance of pharmacological inhibition of galectin-3 for MSC-dependent macrophage polarization towards M2 phenotype and subsequently suppression of aggressive Th1 immune response (18) indicating that MSC-mediated modulation of immune response may be based on production of galectins, as well.

\section{Main cellular targets of MSC-mediated modulation of acute liver injury}

NKT cells accumulate in the liver, and are considered as the major effector cells in the pathogenesis of acute liver failure (19). Along with NKT cells, professional antigen presenting cells (macrophages and DCs) and T lymphocytes play an important role in liver-associated immune and inflammatory responses and are also subject to MSCs-mediated modulation of acute liver failure. Therefore, inhibition of $\mathrm{T}$ cell mediated immune responses evoked by antigen presenting cells is beneficial for treatment of liver diseases.

It was recently demonstrated that the immunosuppressive effect of adipose tissue-derived mesenchymal stem cells (AT-MSCs) in an acute hepatitis model was dependent primarily on the suppression of myeloid lineage and CD4+T cells (20). AT-MSCs-treatment reduced the number of $\mathrm{CD} 11 \mathrm{~b}^{+}$, granulocyte receptor- 1 antigen $(\mathrm{Gr}-1)^{+}$, and $\mathrm{F} 4 / 80^{+}$ macrophages in the liver of Con A-treated mice which was accompanied with the down-regulated expression of inflammatory cytokines (IFN- $\gamma$ and TNF-a) in liver infiltrating CD4 ${ }^{+}$T cells (20) (Figure 1).

In line with results obtained in Con A model, MSCs effectively attenuated the Probionibacteriumprimed, lipopolysaccharide (LPS)-induced fulminant hepatic failure in mice by promoting generation of $\mathrm{CD} 11 \mathrm{c}^{+} \mathrm{MHCI}{ }^{\text {hi }} \mathrm{CD} 80^{\text {lo }} \mathrm{CD} 86^{\text {lo }}$ liver regulatory $\mathrm{DCs}$ from CD11 ${ }^{+}$B220- DC precursors in $\mathrm{PGE}_{2}$-dependent manner (21). These regulatory DCs inhibited differentiation of naïve CD4+ $T$ cells in IFN- $\gamma$ producing CD4+ Th1 cells and promoted expansion of immunosupressive $\mathrm{CD}^{+} \mathrm{CD}_{25}{ }^{+} \mathrm{FoxP}^{+}$Tregs, in TGF- $\beta$ - and IL-10-dependent manner (21).

\section{MSC-mediated attenuation of acute liver inflammation: cell-to cell contact and/or continued delivery of soluble molecules}

MSCs have emerged as an important therapeutic tool in regenerative hepatology due to their ability to differentiate into hepatocytes, thereby providing huge potential to treat liver injuries (2). However, beneficial effects of MSCs may not be restricted to hepatocyte restoration alone, but also may be a consequence of their paracrine effects involved in suppression of detrimental immune response in the liver.

Several preclinical studies suggested that MSCs may attenuate liver injury in paracrine manner and that MSC-CM or MSC-derived molecules, might function as an alternative tool versus direct transplantation of MSCs in the treatment of immune-mediated acute liver failure (22-25).

In several murine models of acute liver failure, administration of MSC-CM significantly reduce liver infiltration of inflammatory cells, attenuated apoptosis and increased proliferation of hepatocytes enabling better liver regeneration and improving survival rate (22-25). Computed tomography of adoptively transferred leukocytes demonstrated that MSC-CM functionally diverts immune cells from the injured livers indicating that altered leukocyte migration by MSC-CM may account for the reduced liver infiltration of immune cells (22). In addition, MSC-CM therapy, mainly mediated by IL-6 and fibrinogen-like protein 1, had profound inhibitory effects on hepatocellular death, resulting in a $90 \%$ reduction of hepatocyte apoptosis, and enhanced the liver regeneration, increasing the proliferation of hepatocytes $(23,24)$.

Opposite to these findings, it was recently showed that successful engraftment of MSCs and not their secretomes are crucial for beneficial effects of MSC-based therapy in acute liver injury (26). Transplanted MSCs managed to significantly ameliorate thioacetamide (TAA)-induced liver injury by promoting proliferation of hepatocytes and by 
inhibiting their apoptosis. These effects were followed by suppressed infiltration of inflammatory $\mathrm{CD}^{+} \mathrm{T}$ cells and $\mathrm{F} 4 / 80^{+}$macrophages in the damaged livers (26). On contrary, injection of MSC-CM only partially ameliorated fulminant liver failure and did not decrease mortality rates of TAA-treated mice (26).

These data support the theory that beneficent effects of MSC-based therapy of acute liver failure is a consequence of their successful engraftment in the liver where they, in cell-to cell contact and through continued delivery of soluble molecules, reduce apoptosis, promote differentiation of hepatocytes and create immunosuppressive environment which enable liver regeneration and recovery (26).

\section{MSC-based therapy of chronic liver inflammation and fibrosis}

In order to elucidate therapeutic potential of MSCs and their products in modulation of chronic liver inflammation and fibrosis, we present the current findings regarding pathogenic role of immune cells in liver fibrosis and describe molecular mechanisms involved in MSC-dependent modulation of chronic liver inflammation with the brief overview of on-going and already published clinical trials that used MSCs for the treatment of immune mediated chronic liver diseases.

\section{Molecular and cellular mechanisms involved in chronic liver inflammation and fibrosis}

After many rounds of injury and repair, hepatocytes reach replicative senescence. Liver fibrosis, which is the precursor to cirrhosis, is the result of the chronic inflammatory reactions and increased deposition of extracellular matrix (ECM) proteins, primarily mediated by activated hepatic stellate cells (HSCs).

HSCs are the major source of fibrillar collagens and other ECM proteins that characterize liver fibrosis. Following chronic liver injury, HSCs undergo a phenotypic switch from quiescent, vitamin A-storing cells to proliferative, a-smooth muscle actin (SMA)-positive, myofibroblast-like cells capable for increased collagen synthesis (27).

Excess production of collagen and other ECM proteins as well as the failure to degrade them are the hallmark of fibrosis. The imbalance of matrix metalloproteinases (MMPs), responsible for the degradation of ECM, and specific endogenous tissue inhibitors of metalloproteinases (TIMPs), results in improper ECM remodeling and fibrosis. Thus, the ultimate goal in case of liver fibrosis is to restore a non-pathological healing process, by inhibiting ECM production and enabling the degradation of its various components.
Among cytokines, TGF- $\beta$ has been described as the most important for the development of liver fibrosis. After binding to its receptor, it induces the activation of a signaling cascade leading to the proliferation of pro-fibrotic cells, myofibroblasts. Accordingly, the TGF- $\beta$ signaling pathway is one of the prime targets for anti-fibrotic therapies and its regulation has been abundantly studied in various pre-clinical and clinical trials.

\section{MSC-mediated modulation of chronic liver inflammation and fibrosis}

Transplantation of MSCs was able to promote partial recovery of liver function and suppression of liver inflammation in several animal models of liver fibrosis (28). Due to their immunomodulatory characteristic, MSCs may suppress chronic inflammation and attenuate fibrosis in the liver by modulating proliferation and apoptosis of HSCs, secretion of pro-fibrotic TGF- $\beta$ and by regulating deposition of collagen.

The immunosuppressive effects of MSCs on continuous inflammation accompanying hepatic fibrosis are mainly attributed to MSC-derived secretomes. MSC-derived soluble factors promote expansion of anti-inflammatory Tregs, and reduce influx of inflammatory Th17 cells in the inflamed liver (26). Moreover, MSC as well as MSC-CM treatment may create anti-inflammatory microenvironment in the liver indirectly through the activation of alternatively activated M2 macrophages, which produce anti-inflammatory cytokines such as C-C motif chemokine ligand 1 (CCL-1) and IL-10 and suppress inflammation (26).

MSCs are able to suppress the proliferation and a-smooth muscle actin (a-SMA) expression in HSCs through cell-cell contact, particularly in Notch dependent manner $(2,29)$. Additionally, several studies have underlined the importance of nerve growth factor (NGF) secreted by MSCs for promoting the apoptosis of HSCs $(25,30,31,32)$. Activated HSCs express the receptor P75, which triggers apoptosis in response to NGF probably by induction of the C-Jun $\mathrm{N}$-terminal kinase (JNK) and nuclear factor kappa-light-chain-enhancer of activated B cells (NF-kB) pathways (32).

Additionally, in several models of fibrosis, transplantation of MSCs resulted with significant decrease in expression and concentration of collagen in the liver, associated with attenuated fibrosis (33-38). Transplantation of MSCs enhanced the activity of MMP-9 and MMP-13 and attenuated activation of TIMP-1 resulting with increased degradation of collagen and other ECM proteins in the fibrotic liver $(13,29,35)$ (Figure 2). 
Modulation of TGF- $\beta$ signaling is one of important mechanisms of MSC-based modulation of liver fibrosis. The decreased production of pro-fibrotic TGF- $\beta$ in liver immune cells, accompanied with attenuated inflammation and reduced fibrosis were noticed in the livers of animals that received either MSCs or MSC-CM (28, 39, 40, 41). In carbon tetrachloride (CCl4) -stimulated chronic liver fibrosis, MSC-CM suppressed fibrosis by attenuating infiltration of pro-fibrogenic TGF- $\beta$-producing F4/80+ macrophages and by promoting apoptosis of HSCs (26) (Figure 2). Additionally, reduced deposition of collagen, decreased expression and production of TGF- $\beta$ in the liver as well as down-regulated serum levels of TGF- $\beta$ were seen in animals that received exosomes previously isolated from MSC-CM (30), suggesting that MSC-mediated attenuation of liver fibrosis may be a consequence of their paracrine actions. In line with these findings, immunomodulatory factors such as IL-10, HGF and TGF- $\beta$, secreted by MSCs, may inhibit the proliferation of HSCs and decrease collagen synthesis $(25,42)$ (Figure 2). MSCs produce IL-10 as a response to IL-6, secreted by activated HSCs, suggesting a dynamic response of MSCs to HSCs in the fibrotic microenvironment of the liver. These results indicated that MSC-secreted soluble factors were mainly responsible for the beneficent effects of MSCs in the therapy of liver fibrosis.

\section{MSCs as novel therapeutic agents in the treatment of chronic liver inflammation and fibrosis}

Over the past few years, MSCs were used in several clinical trials exploring the therapeutic effects of MSCs in the treatment of end-stage liver inflammatory diseases, fibrosis and cirrhosis (Table $1)$.

In patients with liver failure caused by hepatitis $B$ virus (HBV) infection, autologous transplantation of BM-MSCs through hepatic artery provided short-term efficacy in respect to several clinical and biochemical parameters, but long-term outcomes were not markedly improved (43). The improvement of liver function was also observed in patients with hepatitis $\mathrm{C}$ virus (HCV)-related cirrhosis after transplantation of both undifferentiated BM-MSCs and differentiated hepatocyte-like cells, as evaluated by an increased serum levels of prothrombin and albumin and decreased bilirubin and Model for End-Stage Liver Disease (MELD) score (44).

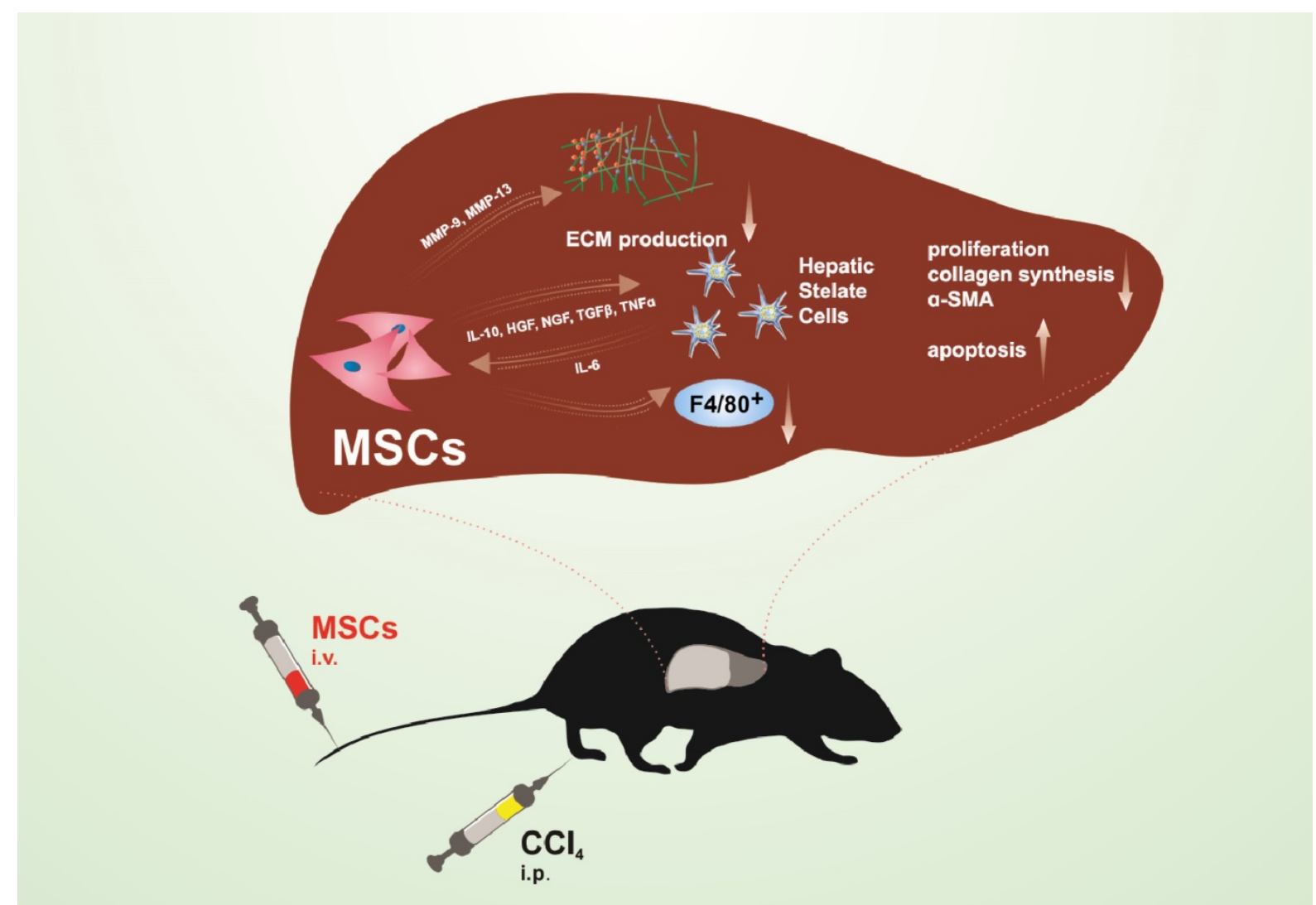

Figure 2. Potential protective mechanisms of MSCs in liver fibrosis. Immunomodulatory factors such as IL-10, HGF, NGF, TGF- $\beta$, and TNF- $\alpha$ secreted by MSCs inhibit proliferation and promote apoptosis of HSCs, leading to reduction in collagen and a-SMA synthesis. MSCs produce MMP-9 and MMP-13 resulting with increased degradation of ECM proteins. MSCs suppress liver fibrosis by attenuating infiltration of pro-fibrotic F4/80+ macrophages in the liver. 
Table 1. Clinical trials using MSCs to treat immune-mediated liver disease

\begin{tabular}{|c|c|c|c|c|c|c|c|c|}
\hline Investigators & Liver disease & Source of MSCs & $\begin{array}{l}\text { Administration } \\
\text { route }\end{array}$ & Dose & $\begin{array}{l}\text { Number of } \\
\text { patients } \\
\text { treated }\end{array}$ & $\begin{array}{l}\text { Number } \\
\text { of control } \\
\text { patients }\end{array}$ & $\begin{array}{l}\text { Follow-up } \\
\text { period }\end{array}$ & Outcomes \\
\hline Peng et al. (43) & $\begin{array}{l}\text { Liver failure due } \\
\text { to chronic HBV } \\
\text { infection }\end{array}$ & $\begin{array}{l}\text { Autologous, } \\
\text { bone marrow }\end{array}$ & $\begin{array}{l}\text { Proper hepatic } \\
\text { artery }\end{array}$ & $\begin{array}{l}3,4 \times \\
10^{8} / \text { patient }\end{array}$ & 53 & 105 & 192 weeks & $\begin{array}{l}\text { Improvement of serum albumin } \\
\text { (Alb), total bilirubin (TBIL), } \\
\text { prothrombin time (PT) and } \\
\text { Model for End-Stage Liver } \\
\text { Disease (MELD) score }\end{array}$ \\
\hline $\begin{array}{l}\text { El-Ansary et al. } \\
(44)\end{array}$ & $\begin{array}{l}\text { Hepatitis C virus } \\
(\mathrm{HCV}) \text {-related } \\
\text { liver cirrhosis }\end{array}$ & $\begin{array}{l}\text { Autologous, iliac } \\
\text { crest }\end{array}$ & Peripheral vein & $1 \times 10^{6} / \mathrm{kg}$ & 15 & 10 & 6 months & $\begin{array}{l}\text { Improvement of liver function } \\
\text { and MELD score }\end{array}$ \\
\hline Jang et al. (46) & $\begin{array}{l}\text { Alcoholic } \\
\text { cirrhosis }\end{array}$ & $\begin{array}{l}\text { Autologous, } \\
\text { bone marrow }\end{array}$ & Hepatic artery & $\begin{array}{l}5 \times 10^{7} / \\
\text { patient, } \\
\text { twice }\end{array}$ & 12 & 0 & 12 weeks & $\begin{array}{l}\text { Histological improvements } \\
\text { Improvement of Child-Pugh } \\
\text { score } \\
\text { Decrease of transforming growth } \\
\text { factor } \beta 1 \text { (TGF- } \beta 1 \text { ), collagen type } \\
1 \text { and a-smooth muscle actin } \\
\text { (a-SMA) }\end{array}$ \\
\hline $\begin{array}{l}\text { Mohamadnejad } \\
\text { et al. (47) }\end{array}$ & Liver cirrhosis & $\begin{array}{l}\text { Autologous, } \\
\text { bone marrow }\end{array}$ & $\begin{array}{l}\text { Cubital vein of } \\
\text { the arm }\end{array}$ & $\begin{array}{l}30 \times 10^{6} / \\
\text { patient }\end{array}$ & 4 & 0 & 1 year & Improvement of MELD score \\
\hline $\begin{array}{l}\text { Kharaziha et al. } \\
(48)\end{array}$ & Liver cirrhosis & $\begin{array}{l}\text { Autologous, } \\
\text { bone marrow }\end{array}$ & $\begin{array}{l}\text { Peripheral or } \\
\text { portal vein }\end{array}$ & $\begin{array}{l}30 \times 10^{6}-50 \\
\times 10^{6} / \\
\text { patient }\end{array}$ & 8 & 0 & 24 weeks & $\begin{array}{l}\text { Improvement of liver function } \\
\text { and MELD score }\end{array}$ \\
\hline Amer et al. (49) & $\begin{array}{l}\text { End-stage liver } \\
\text { failure due to } \\
\text { chronic } \mathrm{HCV} \\
\text { infection }\end{array}$ & $\begin{array}{l}\text { Autologous, } \\
\text { bone marrow }\end{array}$ & $\begin{array}{l}\text { Intrasplenic } \\
(\mathrm{n}=10) \\
\text { or Intrahepatic } \\
\text { (portal) } \\
(\mathrm{n}=10)\end{array}$ & $\begin{array}{l}2 \times 10^{6} / \\
\text { patient }\end{array}$ & 20 & 20 & 6 months & $\begin{array}{l}\text { Improvement of Child-Pugh } \\
\text { score, MELD score, fatigue scale, } \\
\text { performance status }\end{array}$ \\
\hline Zhang et al. (50) & $\begin{array}{l}\text { Chronic hepatitis } \\
\text { B virus (HBV) } \\
\text { infection }\end{array}$ & $\begin{array}{l}\text { Allogeneic, } \\
\text { umbilical cord } \\
\text { (UC)-derived }\end{array}$ & Peripheral vein & $5 \times 10^{5} / \mathrm{kg}$ & 31 & 15 & 1 year & $\begin{array}{l}\text { Improvement of liver function } \\
\text { and MELD score }\end{array}$ \\
\hline Shi et al. (51) & $\begin{array}{l}\text { Chronic HBV } \\
\text { infection }\end{array}$ & UC-derived & Intravenous & $\begin{array}{l}5 \times 10^{5} / \mathrm{kg}, 3 \\
\text { times }\end{array}$ & 24 & 19 & $\begin{array}{l}48 \text { or } 72 \\
\text { weeks }\end{array}$ & $\begin{array}{l}\text { Improvement of liver function } \\
\text { and MELD score }\end{array}$ \\
\hline
\end{tabular}

Significantly improved liver function of post-HCV cirrhotic patients was also noticed after intrasplenic administration of BM-MSCs (45).

Eleven patients with alcoholic cirrhosis safely received autologous BM-MSCs through the hepatic artery. Histological and clinical improvement was observed and the levels of TGF- $\beta 1$, type 1 collagen, and a-SMA were significantly decreased (46).

In two pilot, phase I and I-II clinical trials, autologous bone marrow-derived MSCs (BM-MSCs) were injected into peripheral or portal vein of patients with decompensated liver cirrhosis. Liver function and clinical features were improved and the procedure was safe and well tolerated $(47,48)$. Additionally, the safety and short-term therapeutic effect of autologous transplantation with BM-MSCs-derived hepatocyte-like cells were demonstrated in patients with end-stage liver failure (49). Clinical improvement was verified by MELD score, fatigue scale, performance status and serum albumin level (49). Similarly, umbilical cord-derived MSCs (UC-MSCs) infusion was well tolerated by patients with decompensated cirrhosis and by patients with acute on chronic liver failure, resulting with significant improvement of liver function and increased survival rates $(50,51)$.

\section{Conclusions}

The accumulating evidence showed that MSCs had immunosuppressive and reparative capacities, as well as a significant beneficial effect in immune-mediated liver injury. MSCs are considered to act through multiple mechanisms to coordinate a dynamic, integrated response to liver inflammation and fibrosis, which prevents the progressive distortion of hepatic architecture. The use of MSCs and their products could avoid the serious side effects associated with immunosuppressive drugs and can significantly reduce the need for liver transplantation.

\section{Abbreviations}

$\mathrm{CD}$ : cluster of differentiation; CCl4: carbon tetrachloride; ECM: extracellular matrix, Fas: apoptosis stimulating fragment, FasL: Fas ligand, FoxP3: forkhead box P3; Gr-1: granulocyte receptor-1 antigen; HGF: hepatocyte growth factor; HSCs: hepatic stellate cells; IL: interleukin; LPS: lipopolysaccharide; MHCII: major histocompatibility complex class II; MSCs: mesenchymal stem cells; MSC-CM: mesenchymal stem cell-generated conditioned medium; MMP: matrix metalloproteinase, NGF: nerve growth factor; NF-kB: nuclear factor kappa-light-chain-enhancer of activated B cells; a-SMA: a-smooth mus $\neg$ cle actin; TNF-a: tumor 
necrosis factor $\alpha$; TGF- $\beta$ : transforming growth factor $\beta$; Th: T helper.

\section{Acknowledgments}

This study was supported by "Start Up for Science" grant "The role of Mesenchymal stem cells in acute liver injury" funded by Phillip Morris and Center for Leadership Development, Swiss National Science Foundation project (SCOPES IZ73Z0_152454/1), Serbian Ministry of Science (ON175069, ON175103) and Faculty of Medical Sciences University of Kragujevac (MP01/14 and MP01/12).

We highly appreciate and acknowledge the generous assistance of Mr. Milan Milojevic and Dr. Jasmin Nurkovic who contributed with the creation of the figures in this article.

\section{Competing Interests}

The authors have declared that no competing interest exists.

\section{References}

1. Schuppan D, Afdhal NH. Liver cirrhosis. Lancet. 2008; 371: 838-851.

2. Volarevic V, Nurkovic J, Arsenijevic N et al. Concise review: Therapeutic potential of mesenchymal stem cells for the treatment of acute liver failure and cirrhosis. Stem Cells. 2014; 32: 2818-2823.

3. Gazdic M, Volarevic V, Arsenijevic N et al. Mesenchymal stem cells: a friend or foe in immune-mediated diseases. Stem Cell Rev. 2015; 11: 280-287.

4. Volarevic V, Al-Qahtani A, Arsenijevic $\mathrm{N}$ et al. Interleukin-1 receptor antagonist (IL- 1Ra) and IL-1Ra producing mesenchymal stem cells as modulators of diabetogenesis. Autoimmunity. 2010; 43: 255-263.

5. Volarevic V, Arsenijevic N, Lukic ML et al. Concise review: Mesenchymal stem cell treatment of the complications of diabetes mellitus. Stem Cells. 2011; 29: 5-10.

6. Wu Z, Han $\mathrm{M}$, Chen $\mathrm{T}$ et al. Acute liver failure: mechanisms of immune-mediated liver injury. Liver int. 2010; 30: 782-794.

7. Volarevic V, Milovanovic M, Ljujic B et al. Galectin-3 deficiency prevents concanavalin A-induced hepatitis in mice. Hepatology. 2012; 55: 1954-1964.

8. Volarevic V, Mitrovic M, Milovanovic M et al. Protective role of IL-33/ST2 axis in Con A-induced hepatitis. J Hepatol. 2012; 56: 26-33.

9. Volarevic V, Misirkic M, Vucicevic L et al. Metformin aggravates immune-mediated liver injury in mice. Arch Toxicol. 2015; 89: 437-450.

10. Volarevic V, Paunovic V, Markovic Z et al. Large Graphene Quantum Dots Alleviate Immune-Mediated Liver Damage. ACS Nano. 2014; 8: 12098-12109.

11. Kubo N, Narumi $\mathrm{S}$, Kijima $\mathrm{H}$ et al. Efficacy of adipose tissue-derived mesenchymal stem cells for fulminant hepatitis in mice induced by concanavalin A. J Gastroenterol Hepatol. 2012; 27: 165-172.

12. Zhu $\mathrm{X}, \mathrm{He} \mathrm{B}, \mathrm{Z}$ hou $\mathrm{X}$ et al. Effects of transplanted bone-marrow-derived mesenchymal stem cells in animal models of acute hepatitis. Cell Tissue Res. 2013; 351: 477-486.

13. Heymann F, Hamesch K, Weiskirchen R et al. The concanavalin A model of acute hepatitis in mice. Lab Anim. 2015; 49 (Suppl 1): 12-20.

14. Tagawa Y, Sekikawa K, Iwakura Y. Suppression of concanavalin A-induced hepatitis in IFN-gamma(-/-) mice, but not in TNF-alpha(-/-) mice: role for IFN-gamma in activating apoptosis of hepatocytes. J Immunol. 1997; 159; $1418-1428$

15. Sun K, Xie X, Xie J et al. Cell-based therapy for acute and chronic liver failures: distinct diseases, different choices. Sci Rep. 2014; 4: 6494.

16. Ryu KH, Kim SY, Kim YR et al. Tonsil-derived mesenchymal stem cells alleviate concanavalin A-induced acute liver injury. Exp Cell Res. 2014; 326: 143-154.

17. Simovic Markovic B, Nikolic A, Gazdic M et al. Pharmacological inhibition of Gal-3 in mesenchymal stem cells enhances their capacity to promote alternative activation of macrophages in dextran sulphate sodium-induced colitis. Stem Cells Int. 2016; 2016: 2640746.

18. Volarevic V, Markovic BS, Bojic S et al. Gal-3 regulates the capacity of dendritic cells to promote NKT-cell-induced liver injury. Eur J Immunol. 2015; 45: 531-543.

19. Higashimoto $\mathrm{M}$, Sakai $\mathrm{Y}$, Takamura $\mathrm{M}$ et al. Adipose tissue derived stromal stem cell therapy in murine ConA-derived hepatitis is dependent on myeloid-lineage and CD4+ T-cell suppression. Eur J Immunol. 2013; 43: 2956-2968.

20. Zhang Y, Cai W, Huang Q et al. Mesenchymal stem cells alleviate bacteria-induced liver injury in mice by inducing regulatory dendritic cells. Hepatology. 2014; 59: 671-682.

21. Parekkadan B, van Poll D, Suganuma K et al. Mesenchymal stem cell-derived molecules reverse fulminant hepatic failure. PLoS One. 2007; e941: 1-6.

22. van Poll D, Parekkadan B, Cho $\mathrm{CH}$ et al. Mesenchymal stem cell-derived molecules directly modulate hepatocellular death and regeneration in vitro and in vivo. Hepatology. 2008; 47: 1634-1643.

23. Xagorari A, Siotou E, Yiangou M et al. Protective effect of mesenchymal stem cellconditioned medium on hepatic cell apoptosis after acute liver injury. Int J Clin Exp Pathol. 2013; 6: 831-840.

24. Parekkadan B, van Poll D, Megeed Z et al. Immunomodulation of activated hepatic stellate cells by mesenchymal stem cells. Biochem Biophys Res Commun. 2007; 363: 247-252.

25. Huang $B$, Cheng $X$, Wang $H$, et al. Mesenchymal stem cells and their secreted molecules predominantly ameliorate fulminant hepatic failure and chronic liver fibrosis in mice respectively. J Transl Med. 2016; 14:45.

26. Liu YC, Zou XB, Chai YF et al. Macrophage polarization in inflammatory diseases. Int J Biol Sci. 2014; 10:520-529.

27. Eom YW, Shim KY, Baik SK. Mesenchymal stem cell therapy for liver fibrosis. Korean J Intern Med. 2015; 30: 580-589.

28. Qiao $\mathrm{H}$, Tong $\mathrm{Y}$, Han $\mathrm{H}$ et al. A novel therapeutic regimen for hepatic fibrosis using the combination ofmesenchymal stem cells and baicalin. Pharmazie. 2011; 66: 37-43.

29. Chen S, Xu L, Lin $\mathrm{N}$ et al. Activation of Notch1 signaling by marrow-derived mesenchymal stem cells through cell-cell contact inhibits proliferation of hepatic stellate cells. Life Sci. 2011; 89: 975-981.

30. Li T, Yan Y, Wang B et al. Exosomes derived from human umbilical cord mesenchymal stem cells alleviate liver fibrosis. Stem Cells and Dev. 2013; 22: 845-854.

31. Lin $\mathrm{N}, \mathrm{Hu} \mathrm{K}, \mathrm{Chen} \mathrm{S}$ et al. Nerve growth factor-mediated paracrine regulation of hepatic stellate cells by multipotent mesenchymal stromal cells. Life Sci. 2009; 85: 291-295.

32. Owen A, Newsome PN. Mesenchymal stromal cell therapy in liver disease: opportunities and lessons to be learnt? Am J Physiol Gastrointest Liver Physiol. 2015; 309: G791-G800.

33. Nasir GA, Mohsin S, Khan M et al. Mesenchymal stem cells and Interleukin-6 attenuate liver fibrosis in mice. J Transl Med. 2013; 11: 78.

34. Rabani V, Shahsavani M, Gharavi V et al. Mesenchymal stem cell infusion therapy in a carbon tetrachloride-induced liver fibrosis model affects matrix metalloproteinase expression. Cell Biol Int. 2010; 34: 601-605.

35. Ali G, Mohsin S, Khan M et al. Nitric oxide augments mesenchymal stem cell ability to repair liver fibrosis. J Transl Med. 2012; 10: 75.

36. Pan R, Wang P, Xiang $L$ et al. Delta-like 1 serves as a new target and contributor to liver fibrosis down-regulated by mesenchymal stem cell transplantation. J Biol Chem. 2011; 286: 12340-12348.

37. Wang Y, Lian F, Li J et al. Adipose derived mesenchymal stem cells transplantation via portal vein improves microcirculation and ameliorates liver fibrosis induced by CCl4 in rats. J Transl Med. 2012; 10: 133.

38. Chang Y, Liu J, Lin P et al. Mesenchymal stem cells facilitate recovery from chemically induced liver damage and decrease liver fibrosis. Life Sci. 2009; 517-525.

39. Oyagi S, Hirose $\mathrm{M}$, Kojima $\mathrm{M}$ et al. Therapeutic effect of transplanting HGF-treated bone marrow mesenchymal cells into CCl4-injured rats. J Hepatol. 2006; 44: 742-748.

40. Fang B, Shi M, Liao L et al. Systemic infusion of FLK1+ mesenchymal stem cells ameliorate carbon tetrachloride-induced liver fibrosis in mice. Transplantation. 2004; 78: 83-88.

41. Tsai PC, Fu TW, Chen YM et al. The therapeutic potential of human umbilical mesenchymal stem cells fromWharton's jelly in the treatment of rat liver fibrosis. Liver Transpl. 2009; 15: 484-495.

42. Wang J, Bian C, Liao L et al. Inhibition of hepatic stellate cells proliferation by mesenchymal stem cells and the possible mechanisms. Hepatol Res. 2009; 39: $1219-1228$

43. Mohamadnejad M, Alimoghaddam K, Mohyeddin-Bonab $\mathrm{M}$ et al. Phase 1 trial of autologous bone marrow mesenchymal stem cell transplantation in patients with decompensated liver cirrhosis. Arch Iran Med. 2007; 10: 459-466.

44. Kharaziha P, Hellström PM, Noorinayer B et al. Improvement of liver function in liver cirrhosis patients after autologous mesenchymal stem cell injection: a phase I-II clinical trial. Eur J Gastroenterol Hepatol. 2009; 21: 1199-1205.

45. Amer ME, El-Sayed SZ, El-Kheir WA et al. Clinical and laboratory evaluation of patients with end-stage liver cell failure injected with bone marrow-derived hepatocyte-like cells. Eur J Gastroenterol Hepatol. 2011; 23: 936-941.

46. Peng L, Xie DY, Lin BL et al. Autologous bone marrow mesenchymal stem cell transplantation in liver failure patients caused by hepatitis B: shortterm and long-term outcomes. Hepatology. 2011; 54: 820-828.

47. El-Ansary M, Abdel-Aziz I, Mogawer S et al. Phase II trial: undifferentiated versus differentiated autologous mesenchymal stem cells transplantation in Egyptian patients with HCV induced liver cirrhosis. Stem Cell Rev. 2012; 8: 972-981.

48. Amin MA, Sabry D, Rashed LA et al. Short-term evaluation of autologous transplantation of bone marrow-derived mesenchymal stem cells in patients with cirrhosis: Egyptian study. Clin Transplant. 2013; 27: 607-612 
49. Jang YO, Kim YJ, Baik SK et al. Histological improvement following administration of autologous bone marrow-derived mesenchymal stem cells for alcoholic cirrhosis: a pilot study. Liver Int. 2014; 34: 33-41.

50. Zhang Z, Lin $\mathrm{H}$, Shi M et al. Human umbilical cord mesenchymal stem cells improve liver function and ascites in decompensated liver cirrhosis patients. J Gastroenterol Hepatol. 2012; 27 (Suppl 2): 112-120.

51. Shi M, Zhang Z, Xu R et al. Human mesenchymal stem cell transfusion is safe and improves liver function in acuteon-chronic liver failure patients. Stem Cells Transl Med. 2012; 1: 725-731. 